\title{
Perioperative management and oncological outcomes following radical cystectomy for bladder cancer: a matched retrospective cohort study
}

\section{Prise en charge périopératoire et devenirs oncologiques après une cystectomie radicale pour un cancer de la vessie: une étude rétrospective de cohorte appariée}

\author{
Toby N. Weingarten, MD • Ashley M. Taccolini, RN • Samuel T. Ahle, RN • Kelsey R. Dietz, RN • \\ Shaun S. Dowd, RN • Igor Frank, MD • Stephen A. Boorjian, MD • Prabin Thapa, MS • \\ Andrew C. Hanson, BS · Darrell R. Schroeder, MS · Juraj Sprung, MD, PhD \\ Received: 7 August 2015/Revised: 9 November 2015/Accepted: 25 January 2016/Published online: 5 February 2016 \\ (C) Canadian Anesthesiologists' Society 2016
}

\begin{abstract}
Purpose The immune system plays an important role in tumour progression. Systemic opioids are immunosuppressive; thus, theoretically they may promote tumour spread. Our primary aim was to test the hypothesis that general anesthesia (GA) with spinal analgesia $(S A)$ in patients with bladder cancer undergoing radical cystectomy $(R C)$ will both reduce systemic opioid use and improve oncological outcomes. Since blood transfusions also induce immunosuppression, a secondary aim was to evaluate the effect of perioperative transfusions on oncological outcomes.

Methods One hundred ninety-five patients who underwent RC with GA+SA from 1998-2007 were matched 1:1 to controls who underwent surgery with GA only using propensity scoring and tumour characteristics
\end{abstract}

T. N. Weingarten, MD $(\bowtie) \cdot$ A. M. Taccolini, RN .

S. T. Ahle, RN · K. R. Dietz, RN · S. S. Dowd, RN

J. Sprung, MD, $\mathrm{PhD}(\square)$

Department of Anesthesiology, College of Medicine, Mayo

Clinic, 200 First Street SW, Rochester, MN, USA

e-mail: weingarten.toby@mayo.edu

J. Sprung, MD, $\mathrm{PhD}$

e-mail: sprung.juraj@mayo.edu

I. Frank, MD · S. A. Boorjian, MD

Department of Urology, College of Medicine, Mayo Clinic,

Rochester, MN, USA

P. Thapa, MS - A. C. Hanson, BS - D. R. Schroeder, MS

Health Science Research and Biomedical Statistics and

Informatics, College of Medicine, Mayo Clinic, Rochester, MN,

USA known to be highly associated with oncological outcomes. Medical records were reviewed for use of opioids and transfusions. Outcomes were tumour recurrence, cancerspecific mortality, and all-cause mortality. Survival was estimated using the Kaplan-Meier method, and associations of anesthetic technique and transfusions with outcomes were analyzed using stratified multivariable proportional hazard regression.

Results Systemic opioid use was reduced with $G A+S A$ relative to $G A(P<0.001)$. There was no difference between groups with respect to all-cause mortality (hazard ratio [HR], 1.09; 95\% confidence interval [CI], 0.77 to 1.53; $P=0.636)$, bladder cancer mortality $(H R, 1.03 ; 95 \%$ CI, 0.66 to $1.61 ; P=0.893)$, or cancer recurrence $(H R$, 1.32; $95 \%$ CI, 0.86 to 2.02; $P=0.205)$. Nevertheless, patients who were perioperatively transfused had an increased all-cause mortality (HR, 2.21; 95\% CI, 1.11 to 4.40; $P=0.025)$, and cancer-specific mortality $(H R, 2.61$; 95\% CI, 1.05 to 6.48; $P=0.039$ ).

Conclusions In patients undergoing $R C$, the opioidsparing effect with SA was not associated with improved oncological outcomes, while blood transfusion was associated with increased mortality.

\section{Résumé}

Objectif Le système immunitaire joue un rôle important dans la progression des tumeurs. Les opiö̈des systémiques sont immunosuppressifs, ils pourraient donc, en théorie, promouvoir la propagation des tumeurs. Notre objectif principal était de tester l'hypothèse qu'en ajoutant une analgésie rachidienne $(A R)$ à l'anesthésie générale $(A G)$ chez les patients atteints d'un cancer de la vessie et 
subissant une cystectomie radicale (CR), on réduirait l'utilisation d'opiö̈des systémiques tout en améliorant les devenirs oncologiques. Étant donné que les transfusions sanguines induisent également une immunosuppression, l'un de nos objectifs secondaires était d'évaluer l'effet de transfusions périopératoires sur les devenirs oncologiques.

Méthode Cent quatre-vingt-quinze patients ayant subi une CR avec AG+AR entre 1998 et 2007 ont été appariés à 1:1 à des patients témoins ayant subi une chirurgie avec AG seulement à l'aide des scores de propension et des caractéristiques tumorales connues comme étant fortement associées aux devenirs oncologiques. Les dossiers médicaux ont été passés en revue pour documenter l'utilisation d'opiö̈des et les transfusions. Les critères d'évaluation étaient la récurrence de la tumeur, la mortalité liée spécifiquement au cancer et la mortalité toutes causes confondues. La survie a été estimée à l'aide de la méthode de Kaplan-Meier, et les associations entre technique anesthésique / transfusions et critères d'évaluation ont été analysées à l'aide d'un modèle de régression à risque proportionnel multivariable stratifié.

Résultats L'utilisation d'opioüdes systémiques a été réduite avec une technique $A G+A R$ par rapport à une AG seule $(P<0,001)$. Aucune différence n'a été observée entre les groupes en matière de mortalité toutes causes confondues (rapport de risque [RR], 1,09; intervalle de confiance [IC] $95 \%, 0,77$ à 1,53; $P=0,636)$, de mortalité liée au cancer de la vessie (RR, 1,03; IC $95 \%, 0,66$ à 1,61; $P=0,893)$ ou de récurrence du cancer $(R R, 1,32 ;$ IC $95 \%$, $0,86$ à 2,02; $P=0,205)$. Toutefois, les patients transfusés en période périopératoire ont affiché une augmentation de mortalité toutes causes confondues (RR, 2,21; IC $95 \%$, $1,11$ à 4,40; $P=0,025)$ et de la mortalité spécifiquement liée au cancer (RR, 2,61; IC 95\%, 1,05 à 6,48; $P=0,039)$. Conclusion Chez les patients subissant une CR, l'effet d'épargne opiö̈de de l'AR n'a pas été associé à de meilleurs devenirs oncologiques, alors que la transfusion sanguine a été associée à une mortalité accrue.

Radical cystectomy (RC) and urinary diversion is the mainstay treatment for muscle-invasive bladder cancer, but tumour recurrence is frequent. ${ }^{1}$ The five-year survival rate for patients with pathologically organ-confined bladder cancer is $68 \%$, but for those with extravesicular extension or lymph node involvement, the range is 25 $30 \% .^{1}$ These poor outcomes have created the rationale for investigating multimodal management approaches for these patients.

The immune system plays a prominent role in the host defenses against local or systemic tumour progression. It is important to preserve the function of natural killer (NK) cells, a subset of lymphocytes that spontaneously recognize and kill tumour cells. ${ }^{2,3}$ Several perioperative factors may impair immunologic defenses. Specifically, surgical manipulation disseminates malignant cells into the bloodstream, ${ }^{4}$ surgical stress promotes metastatic growth by affecting immunosuppression through neuroendocrine pathways, ${ }^{2,3}$ and the use of systemic opioids directly inhibits NK cell activity. ${ }^{5-9}$ Finally, blood transfusion induces immunosuppression. ${ }^{10}$

While systemic morphine reduces the NK cell activity, the addition of spinal blockade to general anesthesia in a murine model attenuated the propagation of metastases by surgery. $^{2}$ Neuraxially administered hydrophilic opioids (e.g., morphine, hydromorphone) have low systemic absorption; therefore, they reside within the injected neuraxial compartment with negligible systemic uptake. Furthermore, spinal analgesia uses a fraction of the opioid amount compared with the equianalgesic effect of the same drug given systemically. As a result, substantial systemic opioid-sparing is achieved, which may minimize the immunosuppressive effects from systemic opioids. ${ }^{9,11}$ It has been shown that intrathecal morphine does not affect peripheral lymphocyte (NK cells) function. ${ }^{12,13}$ This entire concept may have clinical implications for oncological patients undergoing surgery with regional anesthesia. ${ }^{14,15}$ These effects are the basis for ongoing research that examines the role of opioid-sparing anesthetic techniques on oncological outcomes. ${ }^{16}$ Nevertheless, there is substantial challenge to such translational work, and clinical studies have not found a consistent association between opioid-sparing and oncological outcomes. ${ }^{17-27}$ One challenge with contemporary anesthetic practices is the impracticality of accomplishing acceptable analgesia without some perioperative opioids. This reality impedes definitive prospective research on whether complete avoidance of perioperative opioids modifies oncological outcomes. The second challenge is the creation of active and control study groups that are well balanced on important oncological prognosticating factors, especially when some factors can be determined only at the time of surgery. Finally, lengthy longitudinal assessments of oncological outcomes, measured in years, are needed in order to accomplish such a study.

There is a lack of studies examining the effect of opioidsparing regional anesthetic techniques regarding oncological outcomes after RC for bladder cancer. We used the Mayo Clinic Radical Cystectomy Registry (MCRCR) to examine the outcomes associated with anesthetic and perioperative management. In this study, we tested the primary hypothesis that adding opioidsparing spinal analgesia to general anesthesia improves oncological outcomes in these patients. Since blood transfusion is also associated with immunosuppression, as a secondary aim, we examined the hypothesis that 
outcomes are worse in patients who receive perioperative blood transfusion.

\section{Methods}

This study was approved by the Institutional Review Board (IRB) of Mayo Clinic, Rochester, MN, USA. Consistent with Minnesota Statute 144.295, we included data only for those patients who provided written authorization to use their medical records for research.

We used the MCRCR, the anesthesia database, and electronic medical records to identify patients who underwent $\mathrm{RC}$ for muscle-invasive bladder cancer from January 1, 1998 to December 31, 2007.

\section{Management of anesthesia and analgesia}

We used the anesthesia database to review the anesthetic technique for RC. During the study period, general anesthesia (only) (GA) was usually induced with propofol or sodium thiopental, fentanyl, midazolam, and succinylcholine or vecuronium. Anesthesia was then maintained with isoflurane, desflurane, or sevoflurane, with or without nitrous oxide. Most typical intraoperative opioids were morphine, hydromorphone, and oxymorphone. When GA was supplemented by spinal analgesia (SA), a single dose of hydrophilic intrathecal opioid was administered-i.e., morphine (0.3-0.6 mg) or hydromorphone $(50-60 \mu \mathrm{g})$, before induction of GA.

\section{Study groups}

All patients who received GA + SA or GA only during the study period were identified using the electronic anesthesia records. We chose to use a matched study design since many patient and tumour pathology characteristics are known to be associated with the outcomes of interest. Using this pool of patients from the cystectomy registry, we calculated a propensity score for each patient from logistic regression analysis with $\mathrm{SA}$ as a dependent variable. All patient characteristics listed in Table 1 were included as explanatory variables, with the exception of invasive disease focality, which was missing for many subjects. The C-statistic for our propensity model was 0.641. Since patient's age, nodal stage, and TNM classification (i.e., cancer staging notation system) are known to be highly associated with oncological outcomes and overall survival, we also used these variables, along with date of surgery, to identify matched sets. Each patient
Table 1 Demographics and cancer characteristics of cystectomy registry patients who received general anesthesia only or general + spinal anesthesia (1998-2007)*

\begin{tabular}{|c|c|c|c|}
\hline \multirow[t]{2}{*}{ Characteristics } & \multicolumn{2}{|c|}{ Anesthesia Management } & \multirow[b]{2}{*}{$\begin{array}{l}P \\
\text { Value }\end{array}$} \\
\hline & $\begin{array}{l}\text { General only } \\
(n=1,166)\end{array}$ & $\begin{array}{l}\text { General }+ \\
\text { spinal }(n=207)\end{array}$ & \\
\hline Age (yr) & $67.9(10.6)$ & $67.8(10.3)$ & 0.92 \\
\hline Sex & & & 0.30 \\
\hline Male & $933(80)$ & $172(83)$ & \\
\hline Female & $233(20)$ & $35(17)$ & \\
\hline $\begin{array}{l}\text { Number of Lymph Nodes } \\
\text { Removed }(n=1,253)\end{array}$ & $9(0,62)$ & $8(0,55)$ & 0.15 \\
\hline $\begin{array}{l}\text { Charlson Comorbidity Index } \\
\qquad(n=1,217)\end{array}$ & & & 0.77 \\
\hline $0-2$ & $474(47)$ & $96(48)$ & \\
\hline$\geq 3$ & $542(53)$ & $105(52)$ & \\
\hline ECOG status $(n=1,247)$ & & & 0.32 \\
\hline $0-1$ & $989(95)$ & $199(97)$ & \\
\hline$\geq 2$ & $52(5)$ & $7(3)$ & \\
\hline $\begin{array}{l}\text { Preoperative hydronephrosis } \\
\qquad(n=1,265)\end{array}$ & & & 0.49 \\
\hline Absent & $761(72)$ & $144(70)$ & \\
\hline Present & $297(28)$ & $63(30)$ & \\
\hline $\begin{array}{l}\text { Primary tumour stage } \\
\quad(n=1,258)\end{array}$ & & & 0.35 \\
\hline pT1 or less & $478(45)$ & $83(40)$ & \\
\hline pT2 & $185(18)$ & 34 (16) & \\
\hline pT3a & 204 (19) & $49(24)$ & \\
\hline pT3b & $115(11)$ & 29 (14) & \\
\hline pT4 & $69(7)$ & $12(6)$ & \\
\hline Nodal stage $(n=1,248)$ & & & 0.03 \\
\hline $\mathrm{pN} 0$ & $745(71)$ & $163(79)$ & \\
\hline $\mathrm{pNX}$ or $\mathrm{pN}+$ & $297(29)$ & $43(21)$ & \\
\hline $\begin{array}{l}\text { Invasive disease focality } \\
\quad(n=818)\end{array}$ & & & 0.71 \\
\hline Unifocal & $593(89)$ & $138(90)$ & \\
\hline Multifocal & $72(11)$ & $15(10)$ & \\
\hline $\begin{array}{l}\text { Lymphovascular invasion } \\
\qquad(n=1,265)\end{array}$ & & & 0.10 \\
\hline Absent & $817(77)$ & $149(72)$ & \\
\hline Present & $241(23)$ & $58(28)$ & \\
\hline $\begin{array}{l}\text { Adjuvant chemotherapy } \\
\qquad(n=1,265)\end{array}$ & & & 0.32 \\
\hline Not received & $912(86)$ & $173(84)$ & \\
\hline Received & $146(14)$ & $34(16)$ & \\
\hline
\end{tabular}

* Values are $n(\%)$ for categorical variables, mean (SD) for age, median (min, max) for number of lymph nodes removed. $P$ values are Chi square for categorical variables and rank-sum or Student's $t$ test as appropriate for continuous variables. $\mathrm{ECOG}=$ Eastern Cooperative Oncology Group 
who received GA + SA was matched 1:1 with a patient who had GA only using the propensity score, pathologic TNM classification stage ( $\leq \mathrm{T} 1 v s \geq \mathrm{T} 2)$, nodal stage (NX vs N0 vs N1/N2/N3), age ( \pm seven years), and date of surgery ( \pm three years). Propensity score matching was performed using the optimal matching algorithm. ${ }^{28,29}$

\section{Data collection}

Data were abstracted from the paper and electronic medical records and entered manually into the web-based Research Electronic Data Capture (REDCap ${ }^{\mathrm{TM}}$ ) system (Version 3.6.7, Vanderbilt University, Nashville, Tennessee). ${ }^{30} \mathrm{We}$ recorded age, American Society of Anesthesiologists (ASA) physical status, and comorbidities, including coronary artery disease (prior coronary artery bypass grafting $[\mathrm{CABG}]$, stent, percutaneous transluminal coronary angioplasty [PTCA], angina, myocardial infarction, or medical treatment for coronary artery disease [CAD]), hypertension (treated), diabetes mellitus (treated), cerebrovascular disease (stroke, transient ischemic attacks), peripheral vascular disease, kidney disease (defined as serum creatinine $\geq 1.5 \mathrm{mg} \cdot \mathrm{dL}^{-1}$ ), and Charlson Comorbidity Index. ${ }^{31}$

Perioperative blood transfusion was defined as transfusion of allogeneic red blood cells, fresh frozen plasma, and/or platelets within the perioperative period (from the start of surgery until discharge from hospital).

\section{Opioid use}

Intrathecal opioid use was recorded but was not included in the calculation of systemic administration. For each patient, we recorded opioids administered in the operating room, recovery room, and for the $48 \mathrm{hr}$ after discharge from the recovery room. All intraoperative and postoperative intravenous and oral opioids given within the first $48 \mathrm{hr}$ were converted to intravenous morphine equivalents. $^{32,33}$

\section{Mayo Clinic Radical Cystectomy Registry}

The clinicopathologic variables recorded in the database included age, sex, Eastern Cooperative Oncology Group (ECOG) performance status, surgical margin status, pathologic tumour stage, tumour histology, lymph node involvement, total number of lymph nodes removed, type of urinary diversion, and receipt of perioperative (neoadjuvant/ adjuvant) chemotherapy. A single urologic pathologist rereviewed all pathologic specimens for histologic classification. Tumour staging followed the American Joint Committee on Cancer/Union Internationale Contre le
Cancer TNM classification, 7th edition. ${ }^{34}$ Pathologic grade, assigned according to the 2004 World Health Organization criteria, was not reported separately as the majority of patients had high-grade disease. Because of the retrospective nature of this study, postoperative follow-up was not standardized. Nevertheless, at our institution, follow-up after RC is recommended quarterly for the first two years postoperatively, semiannually for the next two years, and annually thereafter for patients without evidence of recurrent disease. The registry collects information regarding local recurrence and systemic progression. Oncological evaluation includes history and physical examination, urine cytology, and imaging of the chest, abdomen, and pelvis. For evaluation of survival end points, vital status was identified from death certificates or physician correspondence. For patients followed elsewhere, the MCRCR monitors outcomes annually by correspondence with the patient and the local treating physician.

Follow-up and outcomes

Outcomes measured included all-cause mortality, cancerspecific mortality, and tumour recurrence. In general, vital status was determined from death certificates and/or from yearly correspondence with patients' personal physicians. Death was assigned to bladder cancer when medical records or the death certificate listed bladder cancer as a primary cause. In addition, the cystectomy registry considers death within 30 days after cystectomy as "bladder cancer death" because it resulted from the treatment (i.e., cystectomy impacted the pre-existing cardiovascular disease which led to death).

Statistical power/sample size considerations

The decision to use 1:1 matching was made based on the resource requirements for manual review of medical records. A formal statistical power analysis was not performed. Nevertheless, under the assumption that approximately 250 events would be observed, a proportional hazard analysis would have statistical power (two-tailed, alpha $=0.05$ ) of $80 \%$ to detect a hazard ratio of 1.42 .

Statistical analysis

Characteristics of GA only and GA + SA patients were summarized using descriptive statistics and compared using a two-sample Student's $t$ test, rank-sum test, or Chi square test. Cumulative event rates for all-cause mortality, cancer-specific mortality, and cancer recurrence were 
estimated using the Kaplan-Meier method. These outcomes were analyzed using stratified multivariable proportional hazard regression taking into account the 1:1 matched study design. In addition to anesthesia technique, perioperative blood transfusion was included as an explanatory variable in the model to test our secondary hypothesis that the use of blood products during $\mathrm{RC}$ increases the risk for adverse outcomes. Additional covariates included in the model were the Charlson Comorbidity Index, ECOG classification, number of lymph nodes removed, lymphovascular invasion, use of adjuvant chemotherapy, preoperative hydronephrosis, and preoperative hemoglobin concentrations. The assumption of proportional hazards was assessed using weighted Schoenfeld residuals. ${ }^{35}$ Results are presented as point estimates and 95\% confidence intervals (CIs). All reported $P$ values are two sided. Statistical analyses were done using SAS ${ }^{\circledR}$ statistical software version 9.3 (SAS Institute, Cary, NC, USA).

\section{Results}

We identified 207 patients who underwent $\mathrm{RC}$ with GA+SA during 1998-2007. The majority of these patients (>90\%) received morphine as the intrathecal opioid.

Table 1 shows the demographic and tumour characteristics obtained from the cystectomy registry for the $207 \mathrm{GA}+\mathrm{SA}$ patients as well as all the patients who underwent cystectomy with GA only during the study period. Patients receiving GA only were more likely than the GA+SA patients to have a higher $\mathrm{pNX}$ or $\mathrm{pN}+$ nodal stage (29\% vs $21 \%$, respectively; $P=0.025$ ). Matches could not be identified for 12 of the $207 \mathrm{GA}+\mathrm{SA}$ patients. Fig. 1 shows the standardized differences between anesthesia groups in the entire sample and the 195 matched sets. In the matched sets, the standardized difference was $<0.2$ for all characteristics and $<0.1$ for all characteristics with the exception of the number of lymph nodes removed and lymphovascular invasion.

Demographic and comorbid characteristics for the 195 matched sets are shown in Table 2, while the clinicopathologic tumour characteristics are presented in Table 3. Preoperative comorbidities and cancer-specific characteristics did not differ between groups, with the exception of the number of lymph nodes removed, which was lower in the GA+SA patients than in the GA only patients (median $8 v s$ 10, respectively; $P=0.028$ ).

Table 4 summarizes the duration of anesthesia, perioperative use of systemic opioids (expressed in intravenous morphine equivalents), and transfusion during hospitalization. Importantly, the Appendix includes details regarding the timing and type of blood product

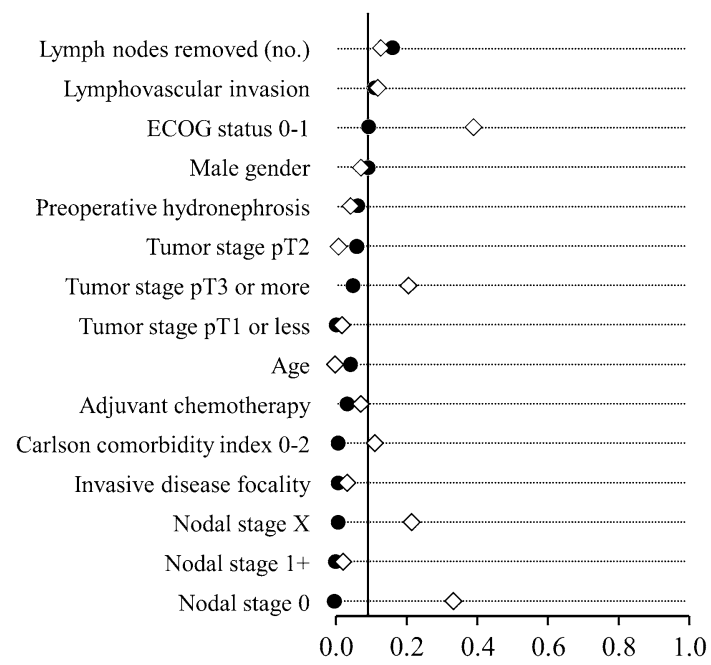

Fig. 1 Standardized differences between anesthesia groups (GA vs GA+SA) for the entire sample (open diamonds) and the 195 matched sets (solid circles). ECOG = Eastern Cooperative Oncology Group

Table 2 Demographics and comorbidities in two study groups

\begin{tabular}{|c|c|c|c|}
\hline \multirow[t]{2}{*}{ Characteristics } & \multicolumn{2}{|c|}{ Anesthesia Management } & \multirow[t]{2}{*}{$P$ Value } \\
\hline & $\begin{array}{l}\text { General only } \\
(n=195)\end{array}$ & $\begin{array}{l}\text { General }+ \text { spinal } \\
(n=195)\end{array}$ & \\
\hline Age & $68.2(10.0)$ & $67.8(10.4)$ & 0.65 \\
\hline Sex & & & 0.36 \\
\hline Male & $155(79)$ & $162(83)$ & \\
\hline Female & $40(21)$ & $33(17)$ & \\
\hline ASA physical status & & & 0.84 \\
\hline II & $86(44)$ & $88(45)$ & \\
\hline III-IV & $109(56)$ & $107(55)$ & \\
\hline $\begin{array}{l}\text { Charlson Comorbidity } \\
\text { Index }\end{array}$ & & & 0.92 \\
\hline $0-2$ & $95(49)$ & $94(48)$ & \\
\hline$\geq 3$ & $100(51)$ & $101(52)$ & \\
\hline Coronary artery disease & $55(28)$ & $59(30)$ & 0.66 \\
\hline Hypertension (treated) & $85(44)$ & $96(49)$ & 0.26 \\
\hline $\begin{array}{l}\text { Stroke/Transitory } \\
\text { ischemic attack }\end{array}$ & $11(6)$ & $7(4)$ & 0.33 \\
\hline $\begin{array}{l}\text { Peripheral vascular } \\
\text { disease }\end{array}$ & $20(10)$ & $16(8)$ & 0.48 \\
\hline Kidney disease* & $24(13)$ & $20(11)$ & 0.58 \\
\hline $\begin{array}{l}\text { Diabetes mellitus } \\
\text { (treated) }\end{array}$ & $22(11)$ & $24(12)$ & 0.75 \\
\hline Preoperative anemia $^{\dagger}$ & $5(3)$ & $9(5)$ & 0.28 \\
\hline
\end{tabular}

Values are $n(\%)$ for categorical variables, mean (SD) for age. $P$ values are Chi square for categorical variables and rank-sum or Student's $t$ test as appropriate for continuous variables

* Serum creatinine $\geq 1.5 \mathrm{mg} \cdot \mathrm{dL}^{-1} ;{ }^{\dagger}$ Hemoglobin concentration $\leq 10$ $\mathrm{g} \cdot \mathrm{dL}-1.56$

ASA $=$ American Society of Anesthesiologists 
Table 3 Cancer characteristics in two study groups*

\begin{tabular}{|c|c|c|c|}
\hline \multirow[t]{2}{*}{ Characteristics } & \multicolumn{2}{|c|}{ Anesthesia Management } & \multirow{2}{*}{$\begin{array}{l}P \\
\text { Value }\end{array}$} \\
\hline & $\begin{array}{l}\text { General only } \\
(n=195)\end{array}$ & $\begin{array}{l}\text { General + spinal } \\
(n=195)\end{array}$ & \\
\hline ECOG status & & & 0.36 \\
\hline $0-1$ & $191(98)$ & $188(96)$ & \\
\hline$\geq 2$ & $4(2)$ & $7(4)$ & \\
\hline $\begin{array}{l}\text { Preoperative } \\
\text { hydronephrosis }\end{array}$ & & & 0.50 \\
\hline Absent & $141(72)$ & $135(69)$ & \\
\hline Present & $54(28)$ & $60(31)$ & \\
\hline Primary tumour stage & & & 0.84 \\
\hline pT1 or less & $75(38)$ & $75(38)$ & \\
\hline pT2 & $39(20)$ & $34(17)$ & \\
\hline pT3a & $48(25)$ & $47(24)$ & \\
\hline pT3b & $21(11)$ & $28(14)$ & \\
\hline pT4 & $12(6)$ & $11(6)$ & \\
\hline Nodal stage & & & 1.00 \\
\hline pNO & $153(78)$ & $153(78)$ & \\
\hline $\mathrm{pNX}$ or $\mathrm{pN}+$ & $42(22)$ & $42(22)$ & \\
\hline $\begin{array}{l}\text { Invasive disease } \\
\quad \text { focality }(n=278)\end{array}$ & & & 0.94 \\
\hline Unifocal & $118(90)$ & $132(90)$ & \\
\hline Multifocal & $13(10)$ & $15(10)$ & \\
\hline $\begin{array}{l}\text { Lymphovascular } \\
\text { invasion }\end{array}$ & & & 0.25 \\
\hline Absent & $149(76)$ & $139(71)$ & \\
\hline Present & $46(24)$ & $56(29)$ & \\
\hline $\begin{array}{c}\text { Number of lymph } \\
\text { nodes removed }\end{array}$ & $10(0,43)$ & $8(0,55)$ & 0.03 \\
\hline $\begin{array}{l}\text { Adjuvant } \\
\text { chemotherapy }\end{array}$ & & & 0.68 \\
\hline Not received & $166(85)$ & $163(84)$ & \\
\hline Received & $29(15)$ & $32(16)$ & \\
\hline
\end{tabular}

*Values are $n(\%)$ for categorical variables, median (min, max) for number of lymph nodes removed. $P$ values are Chi square for categorical variables and rank-sum or Student's $t$ test as appropriate for continuous variables. ECOG $=$ Eastern Cooperative Oncology Group

administration. As expected, systemic opioid use was reduced (on average 54\%), albeit not eliminated, in $\mathrm{GA}+\mathrm{SA}$ patients compared with GA patients $(P<0.001)$.

The median follow-up after RC was $5.2 \mathrm{yr}$ for GA+SA patients and $5.9 \mathrm{yr}$ for GA patients. During follow-up, 261 patients died; 130 of these patients received GA only and 131 received GA + SA. Moreover, of 147 patients who died of bladder cancer, 67 patients received GA only and 80 received $\mathrm{GA}+\mathrm{SA}$.

From proportional hazard regression, there was no difference between the GA+SA and GA only anesthesia groups with respect to all-cause mortality (hazard ratio
[HR], 1.09; 95\% CI, 0.77 to $1.53 ; P=0.636$; Fig. 2 A), bladder cancer mortality (HR, $1.03 ; 95 \% \mathrm{CI}, 0.66$ to 1.61 ; $P=0.893$; Fig. 2 B), or cancer recurrence (HR, 1.32; $95 \%$ CI, 0.86 to 2.02 ; $P=0.205$; Fig. $2 \mathrm{C}$ ).

As expected, patients who received perioperative transfusion ( $\geq 1$ unit) had lower mean (SD) preoperative hemoglobin levels compared with non-transfused patients [12.7 (1.8) g. $\mathrm{dL}^{-1}$ vs 14.2 (1.4) g. $\left.\mathrm{dL}^{-1} ; P<0.001\right)$. Accordingly, preoperative hemoglobin was included as a covariate in the proportional hazards regression analysis. For our secondary hypothesis, i.e., assessing the potential association of blood transfusion with outcomes, we found evidence that the assumption of proportional hazards was violated $(P=0.058, P=0.044$, and $P=0.048$ for overall mortality, bladder cancer mortality, and tumour recurrence, respectively). For this reason, the analysis was restricted to the first five years following RC. From these analyses, patients who received blood transfusions during hospitalization were found to have significantly increased all-cause mortality (HR, 2.21;95\% CI, 1.11 to $4.40 ; P=$ 0.025; Fig. 3 A), and bladder cancer mortality (HR, 2.61; $95 \% \mathrm{CI}, 1.05$ to $6.48 ; P=0.039$; Fig. $3 \mathrm{~B}$ ); however, the difference in the rate of cancer recurrence was not statistically significant between groups (HR, 1.69; 95\% CI, 0.80 to $3.58 ; P=0.171$; Fig. $3 \mathrm{C}$ ).

\section{Discussion}

The main finding of this study was that spinal analgesia with hydrophilic opioids induced an opioid-sparing effect in patients undergoing $\mathrm{RC}$ for bladder cancer. Nevertheless, the magnitude of this opioid-sparing was not associated with improved oncological outcomes. After accounting for the major factors important for prognosis, the use of blood transfusion was associated with worse allcause and cancer-specific survival.

Opioid-sparing anesthesia and oncological outcomes

Surgical stress and systemic opioids impair immunologic host defenses, and the systemic use of morphine within the range of analgesic doses causes suppression of cellular immune system. ${ }^{3,6-8}$ A reduction in systemic opioids has been associated with a reduction in both the recurrence and the progression of cancer in a murine model. ${ }^{2}$ Nevertheless, conducting clinical studies that examine the effects of opioid-sparing anesthetic techniques on oncological outcomes is a complex undertaking. First, despite the use of regional anesthesia, it may be difficult to achieve a true opioid-sparing effect in the perioperative period after major oncological operations. Second, tumours are heterogeneous in their malignant potentials (e.g., pancreas vs prostate), 
Table 4 Duration of anesthesia, perioperative systemic opioid use and perioperative transfusion*

\begin{tabular}{|c|c|c|c|}
\hline \multirow[t]{2}{*}{ Characteristics } & \multicolumn{2}{|l|}{ Anesthesia Management } & \multirow[t]{2}{*}{$P$ Value } \\
\hline & General only $(n=195)$ & General + spinal $(n=195)$ & \\
\hline Duration of Anesthesia (hr) & $5.7[5.1-6.6]$ & $5.7[5.1-6.8]$ & 0.40 \\
\hline \multicolumn{4}{|c|}{ Systemic opioid, morphine equivalents $(\mathrm{mg})^{\dagger}$} \\
\hline Operating room & $45[39-53]$ & $25[15-33]$ & $<0.001$ \\
\hline Recovery room & $5[0-10]$ & $0[0-4]$ & $<0.001$ \\
\hline Post-recovery room, $48 \mathrm{hr}$ & $40[18-67]$ & $9[0-25)$ & $<0.001$ \\
\hline Total $48 \mathrm{hr}$ & $93[63-127]$ & $39[25-60]$ & $<0.001$ \\
\hline Any perioperative transfusion ${ }^{*}$ & $73(37)$ & $78(40)$ & 0.60 \\
\hline Timing of transfusion ${ }^{\S}$ & & & 0.19 \\
\hline Intraoperative only ${ }^{¥}$ & $41(56)$ & $33(42)$ & \\
\hline Intraoperative $\mathrm{F}^{¥}$ and postoperative & $13(18)$ & $15(19)$ & \\
\hline Postoperative only & $19(26)$ & $30(38)$ & \\
\hline
\end{tabular}

* Values are median (interquartile range [IQR]) for duration of anesthesia and morphine equivalents, $n(\%)$ for transfusion variables. $P$ values are Chi square for categorical variables and rank-sum test for continuous variables. ${ }^{\dagger}$ Perioperative systemic opioids used included morphine, fentanyl, hydrocodone, hydromorphone, meperidine, oxycodone, oxymorphone, propoxyphene, and sufentanil. ${ }^{\star}$ All 151 patients who received transfusions received packed red blood cells (PRBC), five patients received non-PRBC products (two received PRBC + fresh frozen plasma, two received PRBC + platelets, and one received PRBC + fresh frozen plasma + platelets).§Analysis was restricted to patients who received transfusion. ${ }^{¥}$ Includes transfusions received in recovery room

and this characteristic may negate identification of effects based on opioid-sparing. ${ }^{24}$ Third, the proper selection of neuraxial opioid is important; some investigators used fentanyl as part of neuraxial analgesia ${ }^{25,26}$; however, this lipophilic opioid given epidurally is promptly systemically absorbed and does not provide a systemic opioid-sparing effect. $^{26,36}$

In the present study, we used SA with morphine, and despite achieving an opioid-sparing effect, the oncological outcomes were not improved. This is in contrast with our previous report where neuraxial anesthetic with morphine and hydromorphone improved oncological outcomes after radical prostatectomy. ${ }^{27} \mathrm{~A}$ possibility for this discrepancy may exist because bladder cancer is more aggressive than prostate adenocarcinoma, which may render it unresponsive to immunomodulatory effects mediated through opioid-sparing. Also RC is a more extensive operation, and the single administration of opioid in the intrathecal space reduces but does not entirely eliminate the perioperative use of systemic opioids. Nevertheless, even with the level of opioid sparing achieved in our study, there was no evidence for a trend of improved outcome. It is unknown whether there exists a dose threshold for systemic opioids beyond which their use adversely affects the immune response. Alternatively, bladder cancer may be less sensitive to the immunomodulation of systemic opioids.

Bladder cancer has a high potential for recurrence, ${ }^{37}$ and the main predictors of death are tumours with an advanced pathologic stage, the presence of extranodal extension, and lymphovascular invasion of disease. ${ }^{38-41}$ All these risk factors were well balanced between our two study groups, as they were either matched or adjusted; therefore, the comparison between groups accounted for the most important elements that determine the prognosis. Despite that, we failed to find an association between the use of opioid-sparing SA and bladder cancer oncological outcomes.

\section{Perioperative transfusion and oncological outcomes}

In our study, perioperative administration of blood was associated with worse survival in models that accounted for prognostically important factors. The potential explanations for the association between blood transfusions and adverse outcomes may be either causative or affected by the presence of unmeasured confounding factors (i.e., transfusion may be a surrogate marker for increased comorbidity, more complex surgery, etc.). It is thought that the "adverse" effects of allogeneic blood transfusions are mediated through mechanisms based on immunosuppression. ${ }^{42-44}$ Nevertheless, autologous or leukocyte-depleted transfusions did not improve outcomes for colorectal cancer patients, ${ }^{45,46}$ suggesting that other non-immune-mediated factors may be responsible for poor outcomes. ${ }^{47,48}$ Based on the information available in the present study, it is not possible to determine whether some unmeasured confounders may have contributed to our findings. Nevertheless, the results of two recent studies showed that perioperative blood transfusions were associated with worse oncological outcomes in patients with bladder cancer, albeit only in univariable 

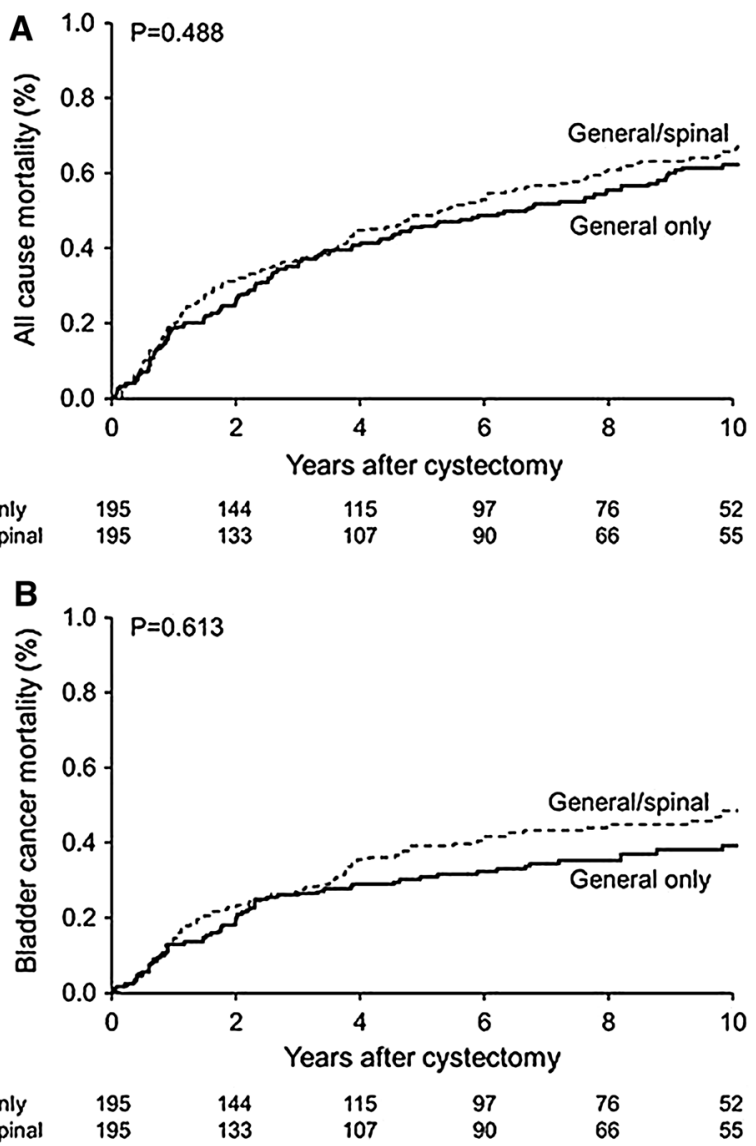

Fig. 2 Cumulative percentage of patients experiencing all-cause death (a), cancer-specific death (b), and cancer recurrence (c) in patients undergoing radical cystectomy with general anesthesia only (general only, solid line) and with general anesthesia supplemented with spinal analgesia (general + spinal analgesia, dashed line). Numbers of patients at risk are shown at zero, two, four, six, eight,

analyses. ${ }^{49,50}$ Further, findings in another large study $(n=$ $2,060)$ from MCRCR showed that the increased number of blood units transfused was associated with reduced cancerspecific survival and all-cause mortality. ${ }^{51}$ The timespan of that study (1980-2005) ${ }^{51}$ partially overlaps with the present report (1997-2007); however, we reconfirmed a strong association between blood transfusion and adverse oncological outcomes on a substantially smaller patient cohort. Therefore, under the assumption that transfusion per se is associated with worse oncological outcomes, efforts should be undertaken to reduce blood transfusions by considering correcting the anemia preoperatively, ${ }^{52,53}$ tolerating lower intraoperative hemoglobin levels, and utilizing techniques that have the potential to reduce intraoperative bleeding. ${ }^{54,55}$

\section{Strengths and limitations}

Important strengths of this study include utilizing a wellstructured RC registry with patients who are receiving

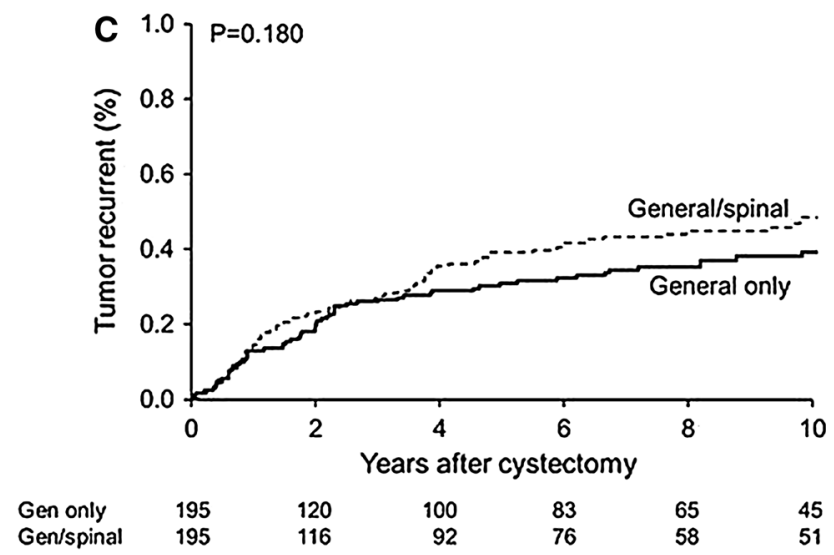

and ten years after surgery. $P$ values are from the stratified proportional hazards regression with covariates included for Charlson Comorbidity Index, Eastern Cooperative Oncology Group classification, number of lymph nodes removed, lymphovascular invasion, use of adjuvant chemotherapy, and preoperative hydronephrosis

longitudinal assessments of oncological outcomes. Nevertheless, this report has all the inherent limitations of an observational retrospective study design. Even the use of propensity matching does not guarantee a balance of unmeasured confounders, and unmeasured or residual confounding by treatment assignment may still persist. Furthermore, non-randomized administration of intrathecal opioid cannot exclude a potential for patient selection bias. Nevertheless, these effects were minimized by our case matching using the most important oncological prognosticating factors. The analysis may not have been sufficiently powered to detect small effects related to the found magnitude of opioid-sparing; however, outcomes in patients who received spinal analgesia were in the "nonprotective" direction. Another limitation was the use of our propensity matching based on the use of regional anesthesia to assess for potential associations between blood transfusions and outcomes. Furthermore, administration of blood products was based on the discretion of the treating physicians. This report 


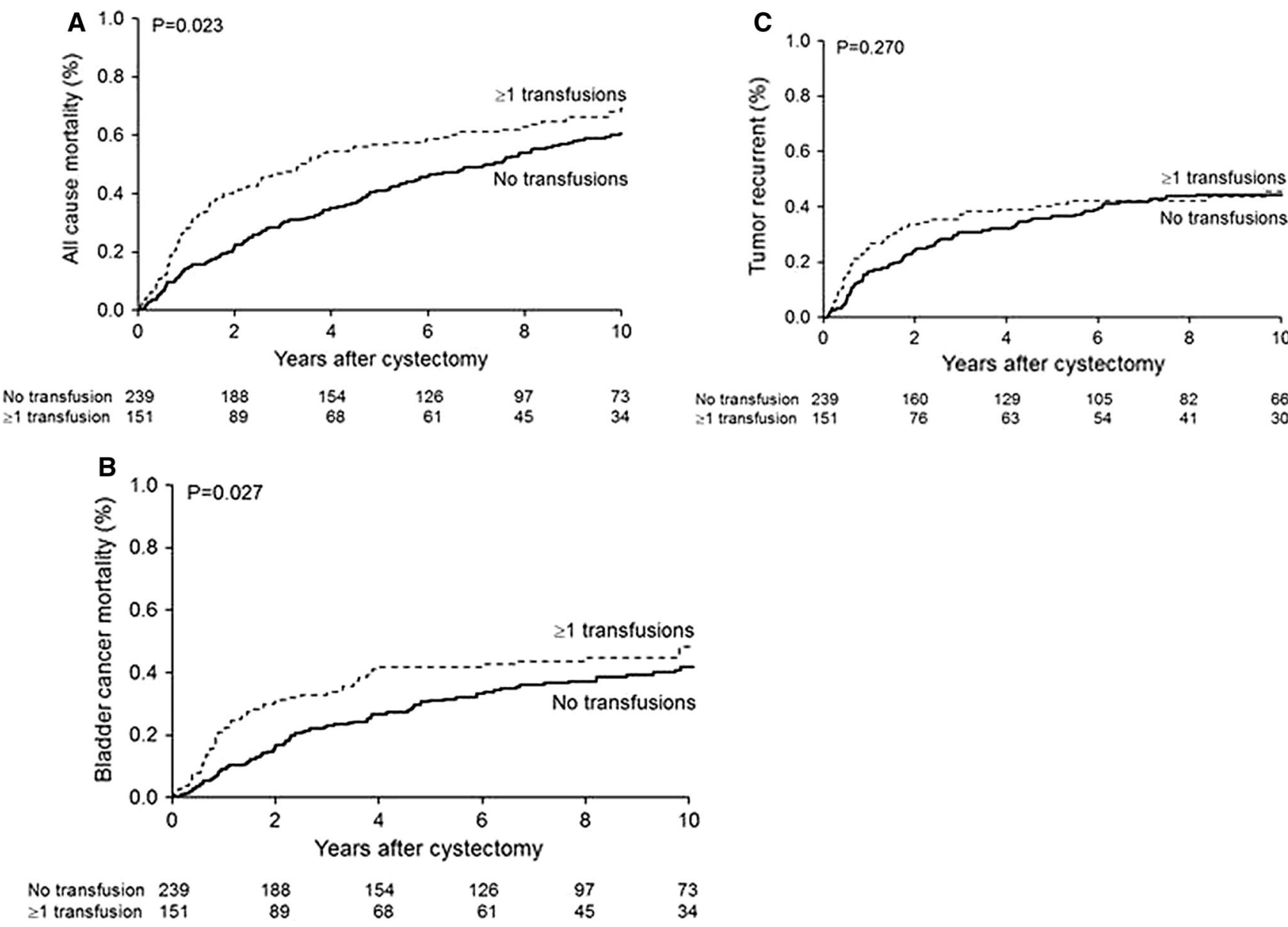

Fig. 3 Cumulative percentage of patients experiencing all-cause death (a), cancer-specific death (b), and cancer recurrence (c) in patients undergoing radical cystectomy stratified by receipt of perioperative blood transfusion: no transfusion received (solid line) and $\geq 1$ blood transfusion received (dashed line). Numbers of patients at risk are shown at zero, two, four, six, eight, and ten years after surgery. $P$ values are from the stratified proportional hazards regression with covariates included for the use of spinal analgesia,

identified a significant association between transfusion and increased cancer mortality (HR, 2.61; $P=0.039$ ), but this association was not statistically significant for cancer recurrence $(\mathrm{HR}, 1.69 ; P=0.171)$. This may be explained by the compliance with follow-up and the timing of followup visits, which are important for identifying recurrence and assigning a date of recurrence. These issues are especially important given the referral nature of our institution. At the same time, determining the date and cause of death is not dependent on how frequently a patient returns for a follow-up visit, as this information is obtained from death certificates.

In conclusion, a reduction in perioperative systemic opioid use achieved with intrathecal morphine analgesia was not associated with improved oncological outcomes following $\mathrm{RC}$ for bladder cancer when compared with

Charlson Comorbidity Index, preoperative hemoglobin, Eastern Cooperative Oncology Group classification, number of lymph nodes removed, lymphovascular invasion, use of adjuvant chemotherapy, and preoperative hydronephrosis. Due to a violation of the proportional hazards assumption when all follow-up was used, the analysis was performed using only follow-up through the first five years following cystectomy

perioperative analgesia provided by systemic opioids. At the same time, perioperative transfusion was associated with worse survival. In view of these results, future studies are needed to address whether correction of anemia before surgery and implementation of other strategies to avoid perioperative transfusions could improve long-term oncological outcomes.

Author contributions: Juraj Sprung, Darrell R. Schroeder, and Toby $N$. Weingarten had full access to all the data in the study and take responsibility for the integrity of the data and the accuracy of the data analysis. Toby N. Weingarten, Igor Frank, Stephen A. Boorjian, Darrell R. Schroeder, and Juraj Sprung were involved in the study conception and design. Samuel T. Ahle, Kelsey R. Dietz, Shaun S. Dowd, and Ashley M. Taccolini, were involved in the acquisition of data. Samuel T. Ahle, Kelsey R. Dietz, Shaun S. Dowd, Ashley M. Taccolini, Toby N. Weingarten, and Juraj Sprung were involved in the analysis and interpretation of data. Stephen A. Boorjian, Darrell 
R. Schroeder, Toby N. Weingarten, Igor Frank, Samuel T. Ahle, Kelsey R. Dietz, Shaun S. Dowd, Ashley M. Taccolini, and Juraj Sprung were involved in drafting the manuscript. Igor Frank, Toby $N$. Weingarten, Darrell R. Schroeder, Juraj Sprung, Samuel T. Ahle, Kelsey R. Dietz, and Shaun S. Dowd, Ashley M. Taccolini were involved in the critical revision of the manuscript for important intellectual content. Toby N. Weingarten, Darrell R. Schroeder, Prabin Thapa, Andrew C. Hanson, and Juraj Sprung were involved in the statistical analysis. Juraj Sprung and Toby N. Weingarten were involved in obtaining funding.

Acknowledgements We sincerely thank Mary E. Marienau PhD CRNA for support and Shonie L. Buenvenida RN for research coordination.

Conflicts of interest None declared.

Funding The Research Electronic Data Capture $\left(\right.$ REDCap $\left.^{\circledR}\right)$ system is supported by a Center for Translational Science Activities grant (UL1 TR000135). This research was carried out with our departmental Small Grant Program. The funders played no role in the design or conduct of the study, including collection, management, analysis, and interpretation of the data and preparation and review of the manuscript.

\section{Appendix}

Transfusion units of blood products transfused in our patients

Transfusion type and timing General only General/spinal $(n=195) \quad(n=195)$

\begin{tabular}{|c|c|c|c|c|}
\hline \multicolumn{5}{|c|}{ Intraoperative (OR/PACU) } \\
\hline \multicolumn{5}{|c|}{ PRBC units } \\
\hline 0 & 141 & $(72 \%)$ & 147 & $(75 \%)$ \\
\hline 1 & 12 & $(6 \%)$ & 17 & $(9 \%)$ \\
\hline 2 & 27 & $(14 \%)$ & 19 & $(10 \%)$ \\
\hline 3 & 8 & $(4 \%)$ & 6 & $(3 \%)$ \\
\hline 4 & 3 & $(2 \%)$ & 3 & $(2 \%)$ \\
\hline 5 & 4 & $(2 \%)$ & 2 & $(1 \%)$ \\
\hline 8 & 0 & $(0 \%)$ & 1 & $(1 \%)$ \\
\hline \multicolumn{5}{|c|}{ FFP units } \\
\hline 0 & 193 & $(99 \%)$ & 195 & $(100 \%)$ \\
\hline 1 & 1 & $(1 \%)$ & 0 & $(0 \%)$ \\
\hline 4 & 1 & $(1 \%)$ & 0 & $(0 \%)$ \\
\hline \multicolumn{5}{|c|}{ Platelet units } \\
\hline 0 & 194 & $(99 \%)$ & 195 & $(100 \%)$ \\
\hline 2 & 1 & $(1 \%)$ & 0 & $(0 \%)$ \\
\hline \multicolumn{5}{|c|}{ Postoperative (after PACU discharge) } \\
\hline \multicolumn{5}{|c|}{ PRBC units } \\
\hline 0 & 165 & $(85 \%)$ & 150 & $(77 \%)$ \\
\hline 1 & 7 & $(4 \%)$ & 11 & $(6 \%)$ \\
\hline 2 & 20 & $(10 \%)$ & 29 & $(15 \%)$ \\
\hline 3 & 2 & $(1 \%)$ & 2 & $(1 \%)$ \\
\hline 4 & 0 & $(0 \%)$ & 3 & $(2 \%)$ \\
\hline
\end{tabular}

Appendix continued

\begin{tabular}{lllll}
\hline Transfusion type and timing & $\begin{array}{l}\text { General only } \\
(n=195)\end{array}$ & \multicolumn{2}{l}{$\begin{array}{l}\text { General/spinal } \\
(n=195)\end{array}$} \\
\hline 10 & 1 & $(1 \%)$ & 0 & $(0 \%)$ \\
FFP units & & & & \\
0 & 193 & $(99 \%)$ & 195 & $(100 \%)$ \\
2 & 1 & $(1 \%)$ & 0 & $(0 \%)$ \\
3 & 1 & $(1 \%)$ & 0 & $(0 \%)$ \\
Platelet units & & & & \\
0 & 193 & $(99 \%)$ & 194 & $(99 \%)$ \\
1 & 0 & $(0 \%)$ & 1 & $(1 \%)$ \\
2 & 1 & $(1 \%)$ & 0 & $(0 \%)$ \\
3 & 1 & $(1 \%)$ & 0 & $(0 \%)$ \\
\hline
\end{tabular}

Data are number and percentage (\%)

$\mathrm{FFP}=$ fresh frozen plasma; $\mathrm{OR}=$ operating room; $\mathrm{PACU}=$ postoperative anesthesia care unit. $\mathrm{OR}+\mathrm{PACU}$ was considered in the study as intraoperative blood administration. $\mathrm{PRBC}=$ packed red blood cells

\section{References}

1. Gschwend JE, Dahm P, Fair WR. Disease specific survival as endpoint of outcome for bladder cancer patients following radical cystectomy. Eur Urol 2002; 41: 440-8.

2. Bar-Yosef S, Melamed R, Page GG, Shakhar G, Shakhar K, BenEliyahu $S$. Attenuation of the tumor-promoting effect of surgery by spinal blockade in rats. Anesthesiology 2001; 94: 1066-73.

3. Ben-Eliyahu S, Page GG, Yirmiya R, Shakhar G. Evidence that stress and surgical interventions promote tumor development by suppressing natural killer cell activity. Int J Cancer 1999; 80: 880-8.

4. Yamaguchi K, Takagi Y, Aoki S, Futamura M, Saji S. Significant detection of circulating cancer cells in the blood by reverse transcriptase-polymerase chain reaction during colorectal cancer resection. Ann Surg 2000; 232: 58-65.

5. Vallejo $R$, de Leon-Casasola $O$, Benyamin $R$. Opioid therapy and immunosuppression: a review. Am J Ther 2004; 11: 354-65.

6. Beilin B, Shavit Y, Hart J, et al. Effects of anesthesia based on large versus small doses of fentanyl on natural killer cell cytotoxicity in the perioperative period. Anesth Analg 1996; 82: 492-7.

7. Brand JM, Kirchner H, Poppe C, Schmucker P. The effects of general anesthesia on human peripheral immune cell distribution and cytokine production. Clin Immunol Immunopathol 1997; 83: 190-4.

8. Yeager MP, Colacchio TA, Yu CT, et al. Morphine inhibits spontaneous and cytokine-enhanced natural killer cell cytotoxicity in volunteers. Anesthesiology 1995; 83: 500-8.

9. McCarthy L, Wetzel M, Sliker JK, Eisenstein TK, Rogers TJ. Opioids, opioid receptors, and the immune response. Drug Alcohol Depend 2001; 62: 111-23.

10. Buddeberg F, Schimmer BB, Spahn DR. Transfusiontransmissible infections and transfusion-related immunomodulation. Best Pract Res Clin Anaesthesiol 2008; 22: 503-17. 
11. Saurer TB, Carrigan KA, Ijames SG, Lysle DT. Suppression of natural killer cell activity by morphine is mediated by the nucleus accumbens shell. J Neuroimmunol 2006; 173: 3-11.

12. O'Connor PJ, Hanson J, Finucane BT. Induced hypotension with epidural/general anesthesia reduces transfusion in radical prostate surgery. Can J Anesth 2006; 53: 873-80.

13. Holmgren L, O'Reilly MS, Folkman J. Dormancy of micrometastases: balanced proliferation and apoptosis in the presence of angiogenesis suppression. Nat Med 1995; 1: 149-53.

14. Sessler DI. Does regional analgesia reduce the risk of cancer recurrence? A hypothesis. Eur J Cancer Prev 2008; 17: 269-72.

15. Byrne K, Levins KJ, Buggy DJ. Can anesthetic-analgesic technique during primary cancer surgery affect recurrence or metastasis? Can J Anesth 2016; . DOI:10.1007/s12630-015-0523-8.

16. ClinicalTrials.gov. Regional Anesthesia and Tumor Outcome. Available from URL: https://clinicaltrials.gov/ct2/results?term= Anesthesia+regional+tumor+outcome $\&$ Search=Search $\quad$ (accessed November 2015).

17. Biki B, Mascha E, Moriarty DC, Fitzpatrick JM, Sessler DI, Buggy DJ. Anesthetic technique for radical prostatectomy surgery affects cancer recurrence: a retrospective analysis. Anesthesiology 2008; 109: 180-7.

18. Wuethrich PY, Hsu Schmitz SF, Kessler TM, et al. Potential influence of the anesthetic technique used during open radical prostatectomy on prostate cancer-related outcome: a retrospective study. Anesthesiology 2010; 113: 570-6.

19. de Oliveira GS, Jr Ahmad S, Schink JC, Singh DK, Fitzgerald $P C, M c$ Carthy $R J$. Intraoperative neuraxial anesthesia but not postoperative neuraxial analgesia is associated with increased relapse-free survival in ovarian cancer patients after primary cytoreductive surgery. Reg Anesth Pain Med 2011; 36: 271-7.

20. Gottschalk A, Ford JG, Regelin CC, et al. Association between epidural analgesia and cancer recurrence after colorectal cancer surgery. Anesthesiology 2010; 113: 27-34.

21. Gupta A, Bjornsson A, Fredriksson M, Hallbook O, Eintrei $C$. Reduction in mortality after epidural anaesthesia and analgesia in patients undergoing rectal but not colonic cancer surgery: a retrospective analysis of data from 655 patients in central Sweden. Br J Anaesth 2011; 107: 164-70.

22. Christopherson R, James KE, Tableman M, Marshall P, Johnson $F E$. Long-term survival after colon cancer surgery: a variation associated with choice of anesthesia. Anesth Analg 2008; 107: 325-32.

23. Ismail H, Ho KM, Narayan $K$, Kondalsamy-Chennakesavan $S$. Effect of neuraxial anaesthesia on tumour progression in cervical cancer patients treated with brachytherapy: a retrospective cohort study. Br J Anaesth 2010; 105: 145-9.

24. Myles PS, Peyton P, Silbert B, et al. Perioperative epidural analgesia for major abdominal surgery for cancer and recurrencefree survival: randomised trial. BMJ 2011; 342: d1491.

25. Tsui BC, Rashiq S, Schopflocher D, et al. Epidural anesthesia and cancer recurrence rates after radical prostatectomy. Can J Anesth 2010; 57: 107-12.

26. Sprung J, Scavonetto F, Yeoh TY, et al. Outcomes after radical prostatectomy for cancer: a comparison between general anesthesia and epidural anesthesia with fentanyl analgesia: a matched cohort study. Anesth Analg 2014; 119: 859-66.

27. Scavonetto F, Yeoh TY, Umbreit EC, et al. Association between neuraxial analgesia, cancer progression, and mortality after radical prostatectomy: a large, retrospective matched cohort study. Br J Anaesth 2014; 113(Suppl 1): i95-102.

28. Rosenbaum PR. Optimal matching for observational studies. J Am Stat Assoc 1989; 84: 1024-32.

29. Gu XS, Rosenbaum PR. Comparison of multivariate matching methods: structures, distances, and algorithms. J Comput Graph Stat 1993; 4: 405-20.
30. Harris PA, Taylor R, Thielke R, Payne J, Gonzalez N, Conde JG. Research electronic data capture (REDCap) — a metadata-driven methodology and workflow process for providing translational research informatics support. J Biomed Inform 2009; 42: 377-81.

31. Charlson M, Szatrowski TP, Peterson J, Gold J. Validation of a combined comorbidity index. J Clin Epidemiol 1994; 47: 1245-51.

32. American Pain Society. Principles of Analgesic Use in the Treatment of Acute Pain and Cancer Pain. 4th ed. Skokie, IL: American Pain Society; 1999.

33. McPherson $M L$. Demistifying Opioid Calculations: A Guide to Effective Dosing. American Society of Health System Pharamacists; 2009: 161.

34. Edge SB, Compton CC. The American Joint Committee on Cancer: the 7th edition of the AJCC cancer staging manual and the future of TNM. Ann Surg Oncol 2010; 17: 1471-4.

35. Grambsch PM, Therneau TM. Proportional hazards tests and diagnostics based on weighted residuals. Biometrika 1994; 81: 515-26.

36. Sandler AN, Stringer D, Panos L, et al. A randomized, doubleblind comparison of lumbar epidural and intravenous fentanyl infusions for postthoracotomy pain relief. Analgesic, pharmacokinetic, and respiratory effects. Anesthesiology 1992; 77: $626-34$

37. Ploussard $G$, Shariat $S F$, Dragomir A, et al. Conditional survival after radical cystectomy for bladder cancer: evidence for a patient changing risk profile over time. Eur Urol 2014; 66: 361-70.

38. Clifton MM, Psutka SP, Boorjian SA, et al. Cancer-specific mortality following radical cystectomy for bladder cancer with lymph node involvement: impact of pathologic disease features and adjuvant chemotherapy. World J Urol 2015; 33: 373-9.

39. Bassi P, Ferrante GD, Piazza N, et al. Prognostic factors of outcome after radical cystectomy for bladder cancer: a retrospective study of a homogeneous patient cohort. J Urol 1999; 161: 1494-7.

40. Kim H, Kim M, Kwak C, Kim HH, Ku JH. Prognostic significance of lymphovascular invasion in radical cystectomy on patients with bladder cancer: a systematic review and meta-analysis. PLoS One 2014; 9: e89259.

41. Stein JP, Lieskovsky $G$, Cote $R$, et al. Radical cystectomy in the treatment of invasive bladder cancer: long-term results in 1,054 patients. J Clin Oncol 2001; 19: 666-75.

42. Cata JP, Wang H, Gottumukkala V, Reuben J, Sessler DI. Inflammatory response, immunosuppression, and cancer recurrence after perioperative blood transfusions. Br J Anaesth 2013; 110: 690-701.

43. Vamvakas EC. Possible mechanisms of allogeneic blood transfusion-associated postoperative infection. Transfus Med Rev 2002; 16: 144-60.

44. Jensen LS, Andersen AJ, Christiansen PM, et al. Postoperative infection and natural killer cell function following blood transfusion in patients undergoing elective colorectal surgery. Br J Surg 1992; 79: 513-6.

45. Busch OR, Hop WC, Hoynck van Papendrecht MA, Marquet RL, Jeekel J. Blood transfusions and prognosis in colorectal cancer. N Engl J Med 1993; 328: 1372-6.

46. Busch OR, Hop WC, Marquet RL, Jeekel J. Blood transfusions and local tumor recurrence in colorectal cancer. Evidence of a noncausal relationship. Ann Surg 1994; 220: 791-7.

47. Heiss MM, Mempel W, Delanoff $C$, et al. Blood transfusionmodulated tumor recurrence: first results of a randomized study of autologous versus allogeneic blood transfusion in colorectal cancer surgery. J Clin Oncol 1994; 12: 1859-67.

48. Houbiers JG, Brand A, van de Watering LM, et al. Randomised controlled trial comparing transfusion of leucocyte-depleted or buffy-coat-depleted blood in surgery for colorectal cancer. Lancet 1994; 344: 573-8. 
49. Kluth LA, Xylinas E, Rieken $M$, et al. Impact of peri-operative blood transfusion on the outcomes of patients undergoing radical cystectomy for urothelial carcinoma of the bladder. BJU Int 2014; 113: 393-8.

50. Morgan TM, Barocas DA, Chang SS, et al. The relationship between perioperative blood transfusion and overall mortality in patients undergoing radical cystectomy for bladder cancer. Urol Oncol 2013; 31: 871-7.

51. Linder BJ, Frank I, Cheville JC, et al. The impact of perioperative blood transfusion on cancer recurrence and survival following radical cystectomy. Eur Urol 2013; 63: 839-45.

52. Albers $P$, Heicappell $R$, Schwaibold H, Wolff J, German Association of Urological Oncology Subdivision of the German Cander Society. Erythropoietin in urologic oncology. Eur Urol 2001; 39: 1-8.
53. Milano M, Schneider M. EPO in cancer anemia: benefits and potential risks. Crit Rev Oncol Hematol 2007; 62: 119-25.

54. Nix J, Smith A, Kurpad R, Nielsen ME, Wallen EM, Pruthi RS. Prospective randomized controlled trial of robotic versus open radical cystectomy for bladder cancer: perioperative and pathologic results. Eur Urol 2010; 57: 196-201.

55. Crescenti A, Borghi G, Bignami E, et al. Intraoperative use of tranexamic acid to reduce transfusion rate in patients undergoing radical retropubic prostatectomy: double blind, randomised, placebo controlled trial. BMJ 2011; 343: d5701.

56. Groopman JE, Itri LM. Chemotherapy-induced anemia in adults: incidence and treatment. J Natl Cancer Inst 1999; 91: 1616-34. 